\title{
Thermal Conditions on the International Space Station: Effects of Operations of the Station Main Radiators on the Alpha Magnetic Spectrometer
}

\author{
M. Xie ${ }^{\mathrm{a}, *}$, J. Burger ${ }^{\mathrm{b}}$ \\ ${ }^{a}$ Harbin Institute of Technology, Harbin, 150001, P. R. China \\ ${ }^{b}$ Massachusetts Institute of Technology, Cambridge, MA 02139, USA
}

\begin{abstract}
A thermal model of the Alpha Magnetic Spectrometer on the International Space Station (ISS) has been developed, and Thermal Desktop ${ }^{\circledR}$ (with $\operatorname{RadCAD}^{\circledR}$ ) and SINDA/FLUINT software have been used to calculate the effects of the operations of the ISS Main Radiators on AMS temperatures. We find that the ISS Starboard Main Radiator has significant influence on temperatures on the port side of AMS. The simulation results are used in AMS thermal control operations.
\end{abstract}

Keywords: AMS, ISS Main Radiators Operations, Thermal Environment

\section{Introduction}

The Alpha Magnetic Spectrometer (AMS) is a general purpose high-energy particle physics detector. It was installed on the International Space Station (ISS) on 19 May 2011 to conduct a unique long duration mission (approximately 20 years) of precision cosmic ray measurements in space [1. Figure 1 displays the AMS location 5 on the ISS. Overall, AMS has dimensions of $5 \times 4 \times 3 \mathrm{~m}^{3}$ and mass of 7.5 tons.

The AMS Thermal Control System (TCS) contains more than 1,000 temperature sensors and about 300 heaters to keep temperatures within the allowed limits. Figure 2 shows the distribution of some of the temperature sensors and heaters. The sensors are read out about once per minute and the data set used in this article covers 19 May 2011 to 24 Dec. 2013; hence, for each sensor, over a million readings are available. All temperature measurements have high and low destructive limits, alarm limits and warning limits. The destructive limits are the temperatures beyond which a component could be damaged. The alarm limits are the temperatures beyond which a component should not be operated. The warning limits are normally set 5 ${ }^{\circ} \mathrm{C}$ within the alarm limits.

On the ISS, AMS is affected by ISS configurations such as the positions of the Main Radiators, the positions of Solar Arrays and ISS flight attitudes. It is also affected by external variables, the most important of which is the Solar Beta $(\beta)$ Angle. The $\beta$ Angle is the angle between the solar vector and the plane of the ISS orbit.

\footnotetext{
* Corresponding author

Email address: min.xie@cern.ch (M. Xie )
}

(C) 2016. This manuscript version is made available under the Elsevier user license

http://www.elsevier.com/open-access/userlicense/1.0/ 
Figure 3 shows the sun direction with different $\beta$ Angles. Relative directions on the ISS are given according to aeronautical conventions (port, starboard, ram, wake) with attitude specified in yaw, pitch and roll (Y/P/R). The Main Radiator panels are $23 \mathrm{~m} \times 11 \mathrm{~m}$ each. The positions of the Main Radiators are controlled by the Port Thermal Radiator Rotation Joint (PTRRJ) and the Starboard Thermal Radiator Rotation Joint (STRRJ). In this paper, PTRRJ and STRRJ positions are used to describe the positions of the Main Radiators. The PTRRJ, which is far away from AMS, does not affect AMS temperatures significantly, except under rare conditions (such as very large positive $\beta$ Angles). The STRRJ, which is near AMS, affects AMS temperatures strongly, especially for very negative $\beta$ Angles. This paper studies the effect on AMS of different STRRJ positions at different $\beta$ Angles. These results are used to plan AMS operations and AMS requests to the ISS program. The simulation can also be used to provide guidance for future experiments on the ISS.

\section{External heat exchange}

\section{1. $\beta$ Angle}

The $\beta$ Angle is one of the most important factors affecting AMS temperatures. As shown in Fig. 4 , the $\beta$ Angle has a period of one year from the seasonal change caused by the inclination of the Earth's axis to the ecliptic. This is superimposed on a period of 60 days caused by the precession of the ISS orbit. The AMS port side will be warmer than the starboard side when the $\beta$ Angle is positive and will be cooler when the $\beta$ Angle is negative.

\subsection{STRRJ}

Figure 3 also shows the definition of the STRRJ position on the ISS. The STRRJ is close to the AMS port side; the STRRJ rotational axis is $3.2 \mathrm{~m}$ from the center of AMS. When the $\beta$ Angle is negative, sunlight can be reflected on to AMS for some STRRJ positions. The thermal radiator can also block the view from the AMS port side to deep space, warming AMS. Figure 5 is an example of STRRJ and $\beta$ Angle variation in very negative $\beta$ Angle periods from Oct. 2012 to Jan. 2013. During these periods, the STRRJ was changed from $40+25^{\circ}$ to $+45^{\circ}$ or $+60^{\circ}$.

\section{External heat exchange software tools}

Thermal Desktop ${ }^{\circledR}$ software (version 5.6) and SINDA/FLUINT software (version 5.6) are used to perform the temperature simulations for this paper. Thermal Desktop ${ }^{\circledR}$ with the RadCAD ${ }^{\circledR}$ plug-in can output Radiation Analysis Data files which are used by SINDA to predict the temperatures of AMS. We use a standard Monte Carlo ray-tracing algorithm to compute radiation exchange factors. 


\section{Tuning the thermal model}

The original AMS standalone models were released by the Carlo Gavazzi Space Company (CGS) and the NASA AMS Mission Management Office (MMO) in Houston. MMO uses an ISS model developed by Boeing, and MMO and CGS have made extensive modeling calculations of AMS thermal conditions on the ISS, during the design, construction, testing and flight phases. The Boeing ISS model is not available to non-US persons, so, in order to be able to perform thermal modeling calculations by AMS personnel at CERN, a simplified ISS thermal model was built according to an ISS scaled model drawing [2] 66 temperature sensors on AMS, paired with nodes in the thermal model, were used to tune the thermal model under the typical operational conditions listed in Table 1.

Table 1: Summary of operational conditions for tuning the thermal model

\begin{tabular}{cc}
\hline Parameter & Values (Degrees) \\
\hline$\beta$ Angle & 15 values from -75 to +75 \\
STRRJ position & +25 \\
Solar Array position & Auto track sunlight \\
& (except port side Solar Arrays locked at $280^{\circ \dagger}$ \\
ISS flight attitude $(\mathrm{Y}, \mathrm{P}, \mathrm{R})$ & for $\beta$ Angle $\left.\geq 70^{\circ}\right)$ \\
\hline
\end{tabular}

\section{Results from the Simulations}

Our purpose is to use this thermal model in the planning of AMS daily operations. To analyze the effect of STRRJ positions on AMS temperatures, the simulation was carried out for the following STRRJ positions: namely $-70^{\circ},-25^{\circ}, 0^{\circ},+25^{\circ},+45^{\circ},+90^{\circ}$, and Auto Track ${ }^{\ddagger}$. All simulations are run with the input values of $\beta$ Angle, Solar Array position, and ISS flight attitude shown in Table 1. The simulation results are orbit average temperatures.

\subsection{Analysis of the effect on the TRD Gas System from the STRRJ positions}

On the AMS port side, the temperature of the Transition Radiation Detector (TRD) Gas System (location shown in Fig. 6) [3] is strongly affected by the STRRJ position for some $\beta$ Angles. The TRD Gas Canister, which contains the redundant gas pumps of the TRD Gas System, often gets low temperature warnings when

\footnotetext{
${ }^{\dagger}$ Port side Solar Arrays are locked close to vertical position.

${ }^{\ddagger}$ The ISS Starboard Main Radiator is horizontal at night and edge-on to the sun during daylight.
} 

peratures of the TRD Gas Canister (see Fig. 6) and the bottom of the plate supporting the TRD Gas system (Plate Fin) were chosen for modeling the effect of STRRJ positions. Figure 7 shows the TRD Gas Canister temperature distributions for several STRRJ positions compared with simulation results from this analysis and from the MMO. Generally, both simulations (this analysis and MMO's) agree with the temperature records. model used, and will be further investigated (M. Xie, to be published). The present simulation agrees better with the data for $\beta$ Angles less than $+30^{\circ}$.

Further modeling results are shown in Fig. 8 and Fig. 9 for the whole range of STRRJ angles. As shown in Fig. 8, the hottest temperature of the TRD Gas Canister happens when the $\beta$ Angle is $+65^{\circ}$ with STRRJ $0^{\circ}$. the STRRJ position has a significant effect on the TRD Gas Canister temperature, changing it by at least 5 ${ }^{\circ} \mathrm{C}$ to as much as $15{ }^{\circ} \mathrm{C}$. When the $\beta$ Angle is larger than $+20^{\circ}$, almost all simulated results are at or above the warning limit, and there are no concerns except for $\beta$ Angle $+75^{\circ}$, with the port side Solar Arrays locked close to vertical. There additional shading from the port side Solar Arrays brings the temperature below the warning limit for cases with the STRRJ close to vertical $\left(+90^{\circ}\right.$ and $\left.-70^{\circ}\right)$. For $\beta$ Angles between $-15^{\circ}$ and $+15^{\circ}$, this temperature will be below the warning or even alarm limit. In this range of $\beta$ Angles, changing the STRRJ positions cannot be used to bring the TRD Gas Canister above the limit. AMS operations such as turning on additional heaters are needed. When the $\beta$ Angle is less than $-15^{\circ}$, roughly vertical positions (absolute value greater than $45^{\circ}$ ) of the STRRJ position can help keep the TRD Gas Canister warm.

Especially for $\beta$ Angle values from $-75^{\circ}$ to $-40^{\circ}$, both temperature records and the simulation show that some STRRJ positions result in low temperature warnings for the TRD Gas Canister. To protect the TRD Gas Canister, AMS has requested the ISS to adjust the STRRJ position multiple times. We do not have flight data for all combinations of the $\beta$ Angle and the STRRJ position. This makes simulations important. Because of the possibility that the mechanisms to move the ISS radiators may fail (for example, half of the redundant mechanism for moving the ISS Port Main Radiator is currently not functioning and this has had an effect on STRRJ operations), and because protection of ISS components and astronauts will have priority over AMS thermal requirements, the MMO has suggested installing a thermal blanket on the port side of AMS to reduce temperature variations of the TRD Gas System. The MMO and AMS teams have analyzed the effects of the blanket for various STRRJ positions and $\beta$ Angles and conclude it will be beneficial (M. Xie, to be published). The blanket has been built and installed on AMS in Oct., 2015. Its long term performance over various orbit conditions is being evaluated.

For the Plate Fin sensor in Fig. 9, the hottest temperature occurs when the $\beta$ Angle is $+65^{\circ}$ with STRRJ $0^{\circ}$. The coldest temperature happens when the $\beta$ Angle is $-75^{\circ}$ with STRRJ $-25^{\circ}$. When the $\beta$ Angle value 
is negative, the STRRJ position has a significant effect on this temperature, changing it by at least $5^{\circ} \mathrm{C}$ to as

much as $15{ }^{\circ} \mathrm{C}$.

\subsection{Analysis of effect on the Aluminum Canister from the STRRJ positions}

The Aluminum Canister (AC, see Fig. 6) is the thermally passive mechanical support for the AMS detectors, so its temperatures directly show the effects of the environment, such as the STRRJ positions.

Figure 10 shows the results of simulations for one AC temperature sensor on the port bottom side of AMS, LVCR4 (shown in Fig. 6 and enclosed in a red rectangle in Fig. 10). Under different $\beta$ Angles and STRRJ positions, the hottest temperature of LVCR4 happens when the $\beta$ Angle is $+65^{\circ}$ with STRRJ Auto Track. The coldest temperature happens when the $\beta$ Angle is $-75^{\circ}$ with STRRJ $-25^{\circ}$. When the $\beta$ Angle value is negative, the STRRJ position has a significant effect on the LVCR4 temperature, changing it by at least $5{ }^{\circ} \mathrm{C}$ to as much as $25^{\circ} \mathrm{C}$.

\subsection{Main Radiators of $A M S$}

The major part of the AMS electronics are mounted on the AMS Main Radiators [4], WAKE and RAM (locations shown in Fig. 6). These transfer the bulk of the AMS power dissipation (1,500W out of 2,000W) into space. One sensor is selected on each of these radiators to illustrate the results of the simulations of the STRRJ position. As shown in Fig. 11, the STRRJ position does not affect the AMS RAM Radiator (sensor RR2) since the RAM Radiator does not face the ISS Starboard Main Radiator. Figure 12 shows that the STRRJ position has only a small effect on the WAKE Radiator (sensor WR1) temperature for high positive $\beta$ Angles, but can make as much as a $15{ }^{\circ} \mathrm{C}$ difference when the $\beta$ Angle is negative. All values are well within the temperature warning limits.

\subsection{Power Distribution System (PDS)}

The AMS PDS is located on the WAKE Radiator 44 (location shown in Fig. 6). It is the main AMS power supply and has the largest local heat dissipation $(330 \mathrm{~W})$. It is affected by the STRRJ position as is everything on the WAKE Radiator. The simulation results show (Fig. 13) that the PDS temperature stays within limits for the simulated cases. The STRRJ position has only a small effect on the PDS_B temperature for high positive $\beta$ Angles, but can make more than $10{ }^{\circ} \mathrm{C}$ difference when the $\beta$ Angle is negative. All values stay well within its warning limits for the operational conditions modeled for this paper. The PDS can get too hot when the ISS flies in an unusual attitude, such as $-90^{\circ}$ yaw. With this attitude and very negative beta angles, the sun shines continuously on the AMS wake radiator and this makes the PDS too hot.

\subsection{Analysis of detectors' sensors close to the ISS Starboard Main Radiator}

The STRRJ position can affect the detector temperatures on the bottom of the port side of AMS, such as parts of the Electromagnetic Calorimeter (ECAL) [5] and the Ring Imaging Cerenkov Counter (RICH) [6] 
(locations shown in Fig. 6). Figure 14 shows the locations of the ECAL sensors, and we choose the middle sensor on the port side, ECAL_P3 (enclosed in a red rectangle in Fig. 14), to analyze. In Fig. 14, the ECAL_P3 temperature changes more than $10{ }^{\circ} \mathrm{C}$ with different STRRJ positions, but stays within its limits.

The RICH is above the ECAL, but also at the bottom of AMS. The chosen sensor, RICH_702_7074, is on 15) by more than $10^{\circ} \mathrm{C}$ with different STRRJ positions, but stays within the its limits.

\section{Conclusions}

The STRRJ position affects AMS temperatures differently in different $\beta$ Angle ranges under the operational conditions ( $\beta$ Angle, Solar Array position and ISS flight attitude) shown in Table 1. A summary of conclusions based on the results of the model simulations used for this paper follows:

- When the $\beta$ Angle is less than $-15^{\circ}$, the AMS port side is colder for the STRRJ position $0^{\circ}$ or Auto-Track to sunlight than for STRRJ positions which keep the ISS Starboard Main Radiator more vertical. The difference between coldest and hottest cases can reach $25^{\circ} \mathrm{C}$. To protect sensitive AMS components, the ISS Starboard Main Radiator needs to be close to vertical for some $\beta$ Angles. If this is not possible, the port side of AMS can be protected with the planned additional thermal blanket.

- When the $\beta$ Angle is larger than $+30^{\circ}$, the AMS port side is hotter when the ISS Starboard Main Radiator is horizontal than when it is vertical. The temperature difference between coldest and hottest cases for different STRRJ positions can reach $13{ }^{\circ} \mathrm{C}$. To keep AMS warm enough, we must avoid vertical Starboard Main Radiator positions which shade AMS. If this is not possible, the additional blanket will also help.

- For $\beta$ Angles between $-15^{\circ}$ and $+30^{\circ}$, the STRRJ position barely affects the temperature. The TRD Gas Canister temperature can be below the warning or alarm limit for $\beta$ Angles close to $0^{\circ}$ as shown in Fig. 7. The additional blanket will reduce the need for AMS operations in this case.

- The simulations are important to predict the effect of possible unusual conditions, since we do not have operational data for all combinations of $\beta$ Angle, STRRJ position, ISS flight attitude, etc.

- The simulations can also serve as guidelines for other ISS experiments.

\section{Acknowledgments}

This work was supported by the China Scholarship Council and the U.S. Department of Energy. We thank Craig Clark of the NASA AMS MMO team for his extensive simulation work. 


\section{References}

[1] Aguilar, et al., First Result from the Alpha Magnetic Spectrometer on the International Space Station: Precision Measurement of the Positron Fraction in Primary Cosmic Rays of 0.5-350 GeV, Phys. Rev. Lett. 110 (2013) 141102. doi:10.1103/PhysRevLett.110.141102. URL http://link.aps.org/doi/10.1103/PhysRevLett.110.141102

[2] ISS configuration, http://www.nasa.gov/mission_pages/station/multimedia/scalemodel/.

[3] T. Kirn, T. Siedenburg, The AMS-02 transition radiation detector, Nuclear Instruments and Methods in Physics Research Section A: Accelerators, Spectrometers, Detectors and Associated Equipment 535 (2004) 口 165 - 170, Proceedings of the 10th International Vienna Conference on Instrumentation. doi:10.1016/j . nima.2004.07.273.

URL http://www.sciencedirect.com/science/article/pii/S0168900204015955

[4] K. Wang, J. Li, Z. Cui, N. Wang, Q. Sun and L. Cheng, Operations of the thermal control system for Alpha Magnetic Spectrometer electronics following the beta angle of the International Space Station, Nuclear Instruments and Methods in Physics Research Section A: Accelerators, Spectrometers, Detectors and Associated Equipment 767 (2014) 235 - 244. doi:10.1016/j.nima.2014.08.010.

URL http://wWw.sciencedirect.com/science/article/pii/S0168900214009309

[5] F. Cadoux, et al., The AMS-02 electromagnetic calorimeter, Nuclear Physics B - Proceedings Supplements 113 (2002) 159 - 165. doi:10.1016/S0920-5632(02)01836-4.

URL http://www.sciencedirect.com/science/article/pii/S0920563202018364

[6] M. Buénerd, The RICH counter of the AMS experiment, Nuclear Instruments and Methods in Physics Research Section A: Accelerators, Spectrometers, Detectors and Associated Equipment 502 (2003) 158 162. doi:10.1016/S0168-9002(03)00267-5

URL http://www.sciencedirect.com/science/article/pii/S0168900203002675 


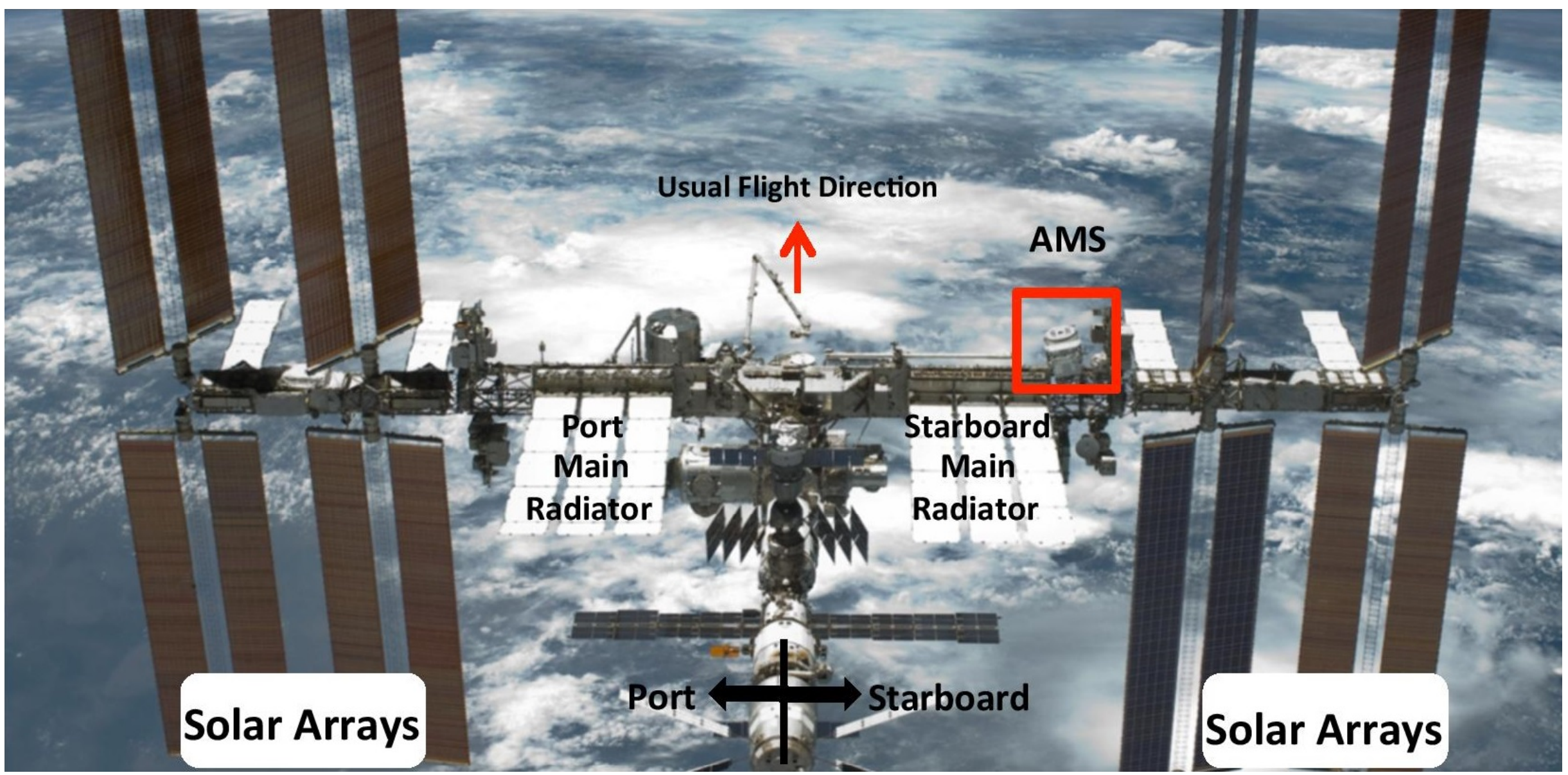

Figure 1: The ISS and the location of AMS on the ISS. The locations of the ISS Port and Starboard Main Radiators and Solar Arrays are shown. For reference, the ISS is $110 \mathrm{~m}$ across and AMS 3m. As seen AMS is mounted on the ISS with a $12^{\circ}$ roll to Port. 
TRD

24 Heaters

482 Temperature Sensors

\section{AMS Thermal Control System}

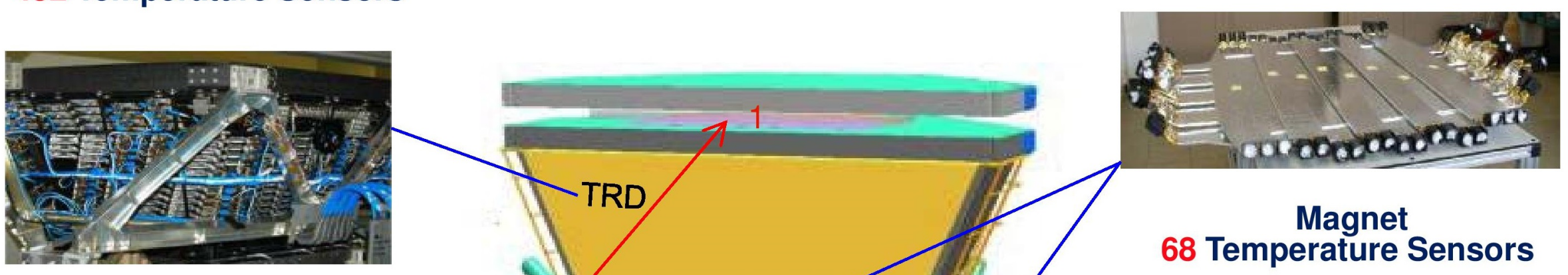

Silicon Tracker

32 Heaters

142 Temperature Sensors

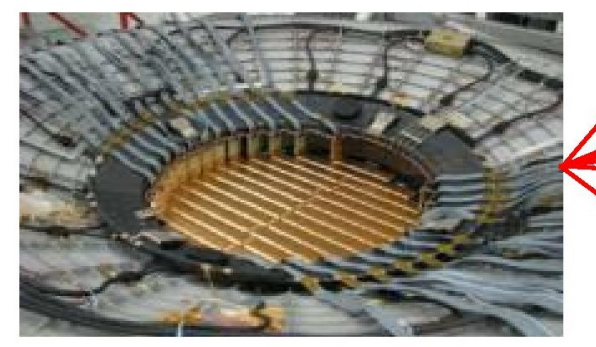

ECAL

16 Heaters

80 Temperature Sensors
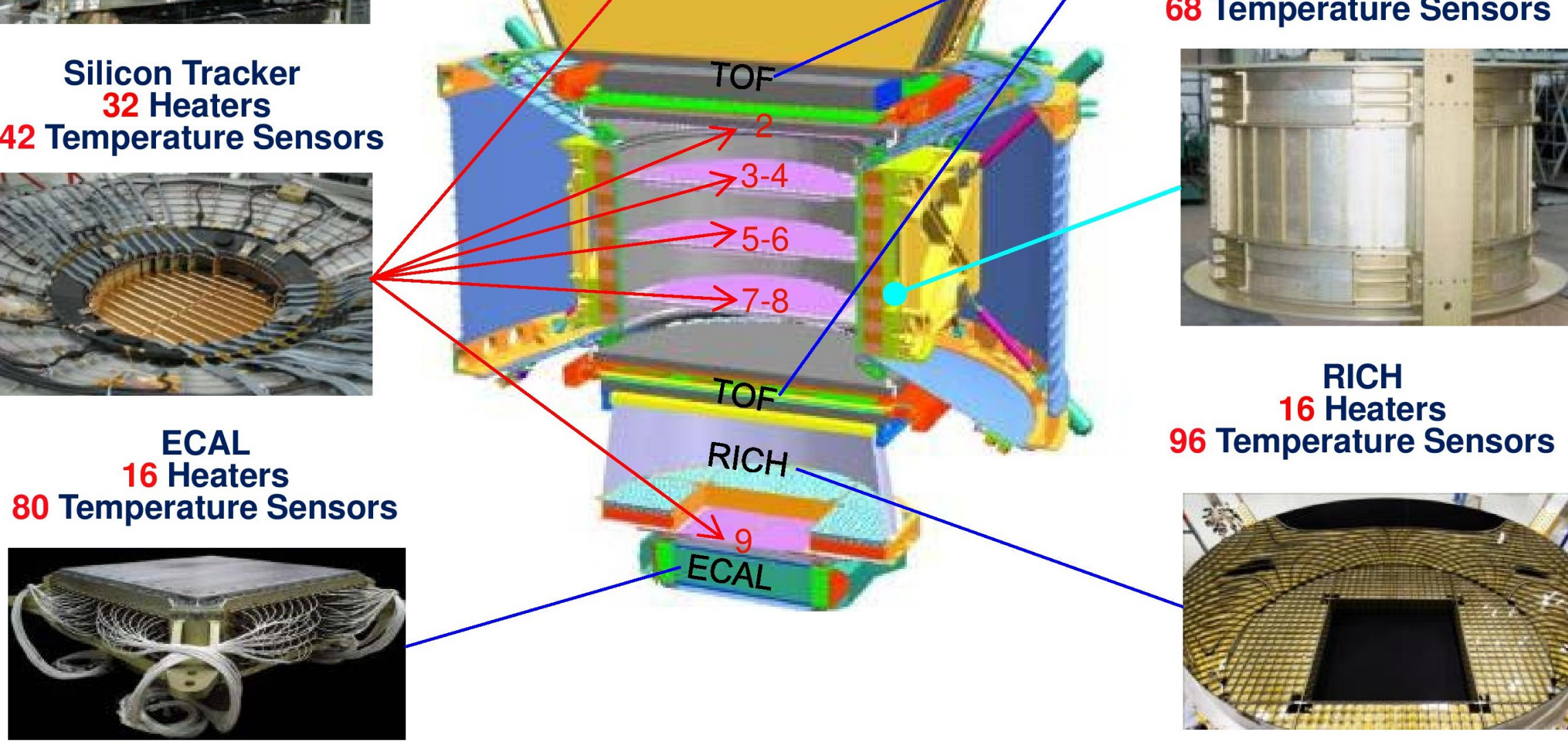

RICH

16 Heaters

96 Temperature Sensors

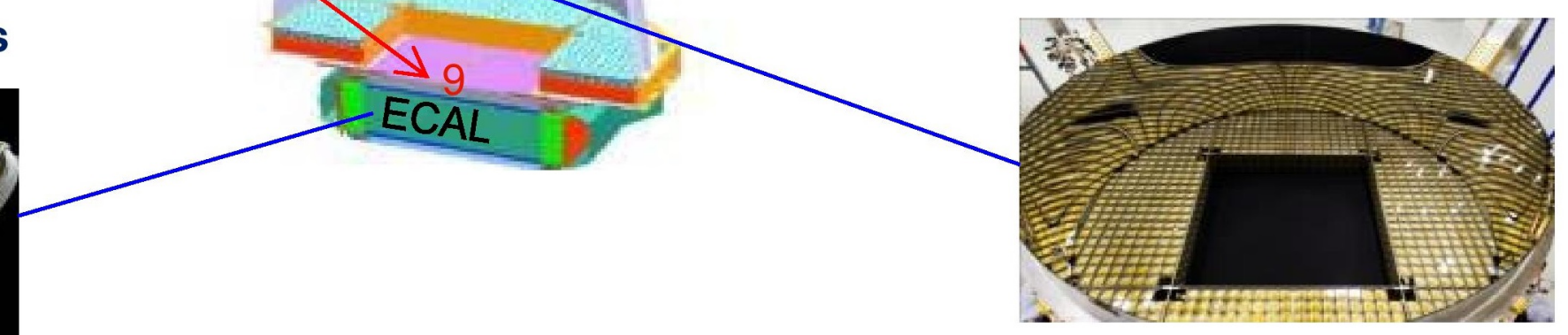

Figure 2: Distribution of some AMS Thermal Control System components. There are more than 1000 temperature sensors and about 300 heaters in total. 


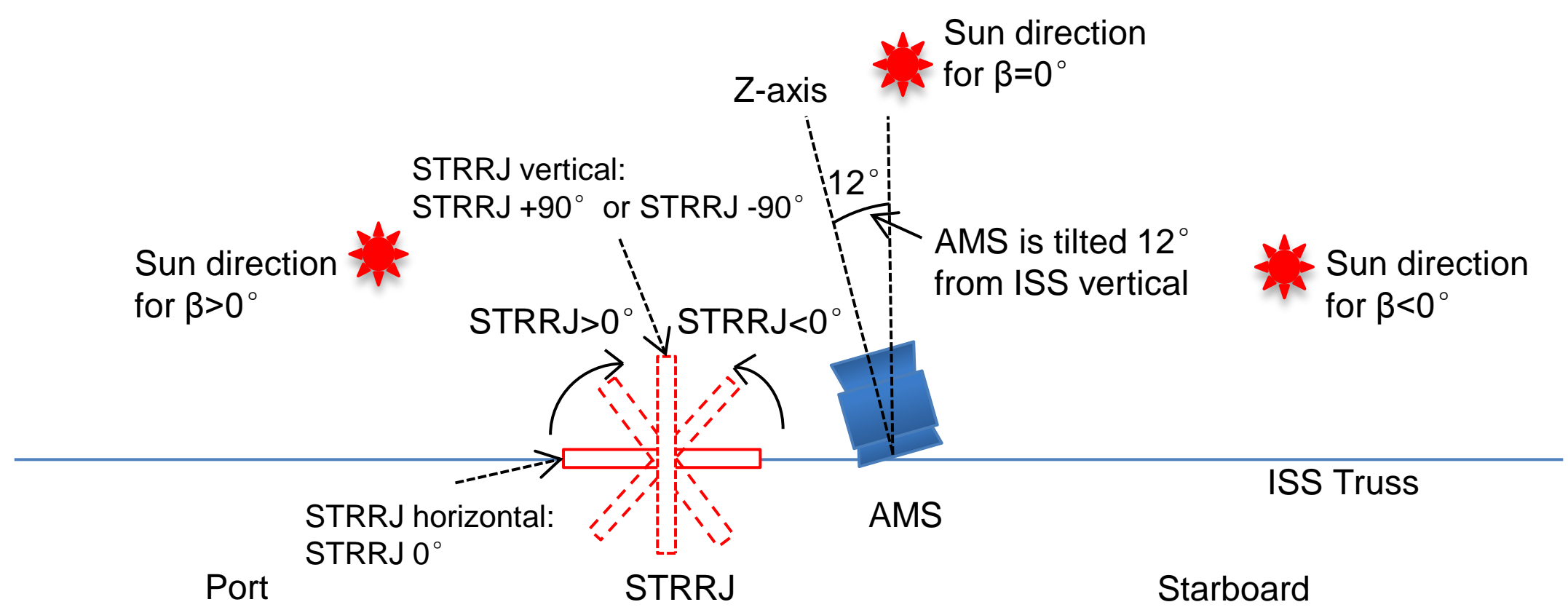

Figure 3: Schematic view in the usual ISS flight direction. Geometrical relation among the Sun, AMS and ISS Truss and STRRJ. The sign conventions for $\beta$ Angle (sun position) and STRRJ position are shown. 


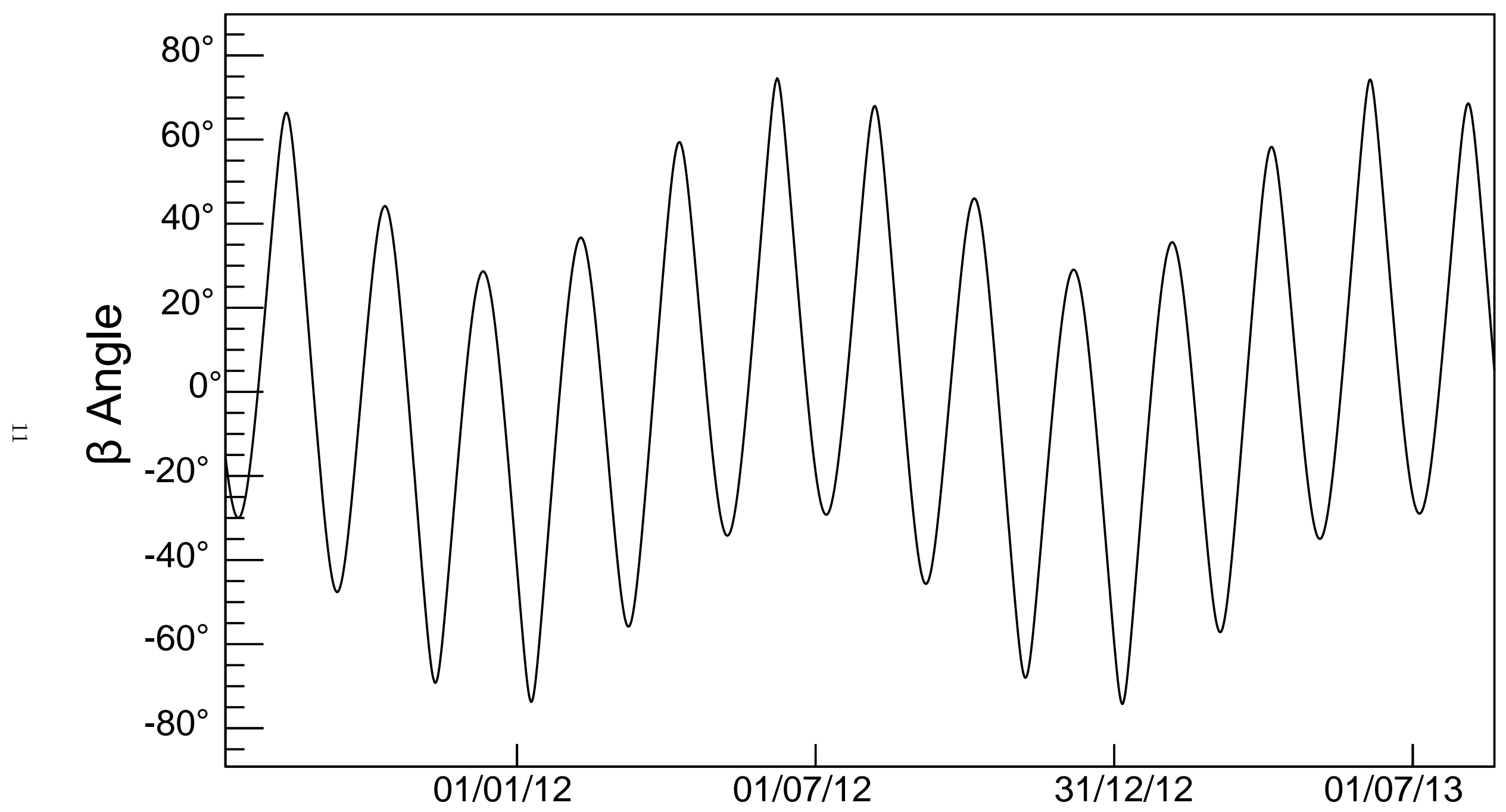

Figure 4: The $\beta$ Angle variation from 19 May 2011 to 31 July 2013 in units of DD/MM/YY. 


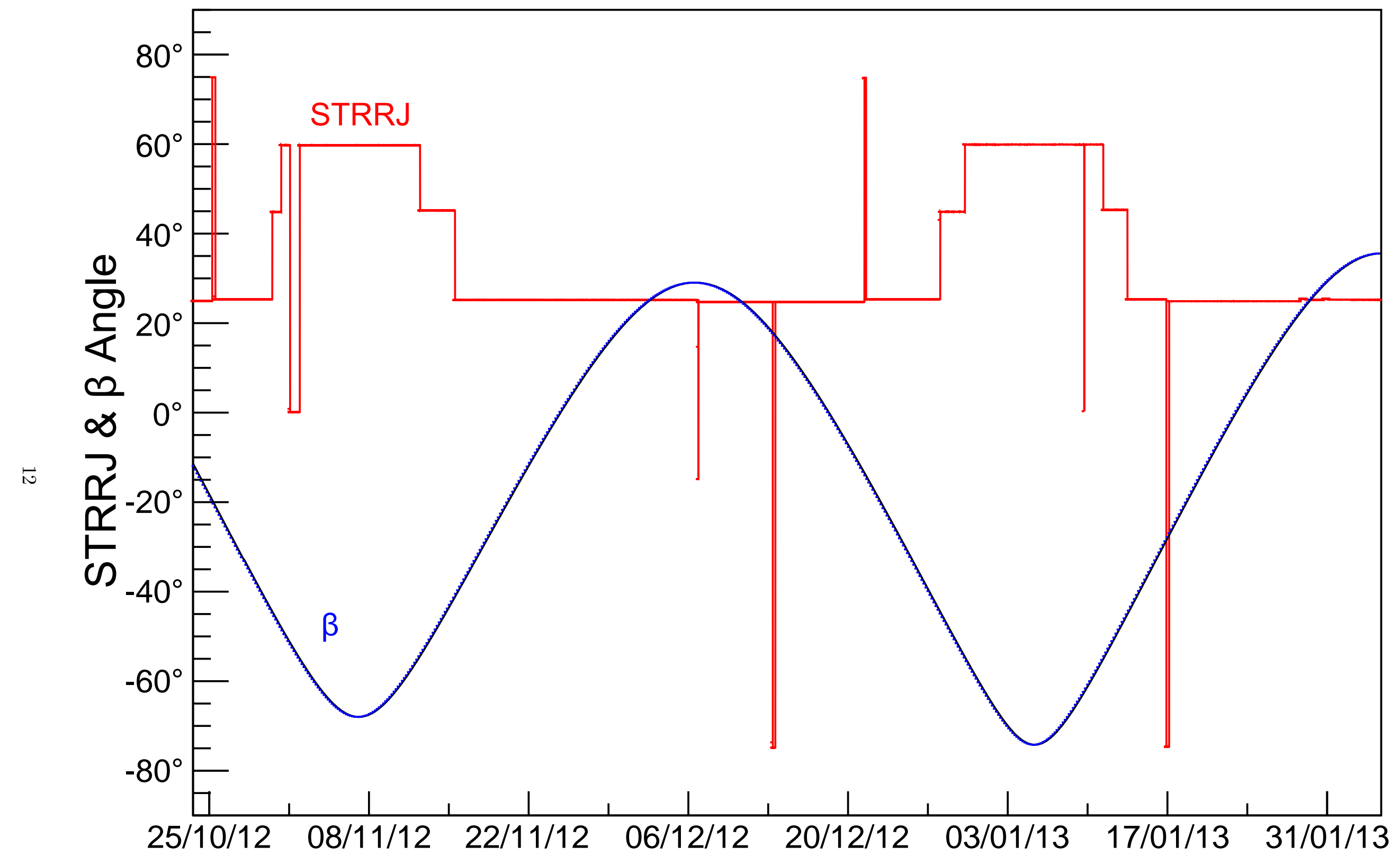

Figure 5: STRRJ (red joined lines) and $\beta$ Angle (blue curve) variation in very negative $\beta$ Angle periods during Oct. 2012 to Jan. 2013 in units of $\mathrm{DD} / \mathrm{MM} / \mathrm{YY}$. 


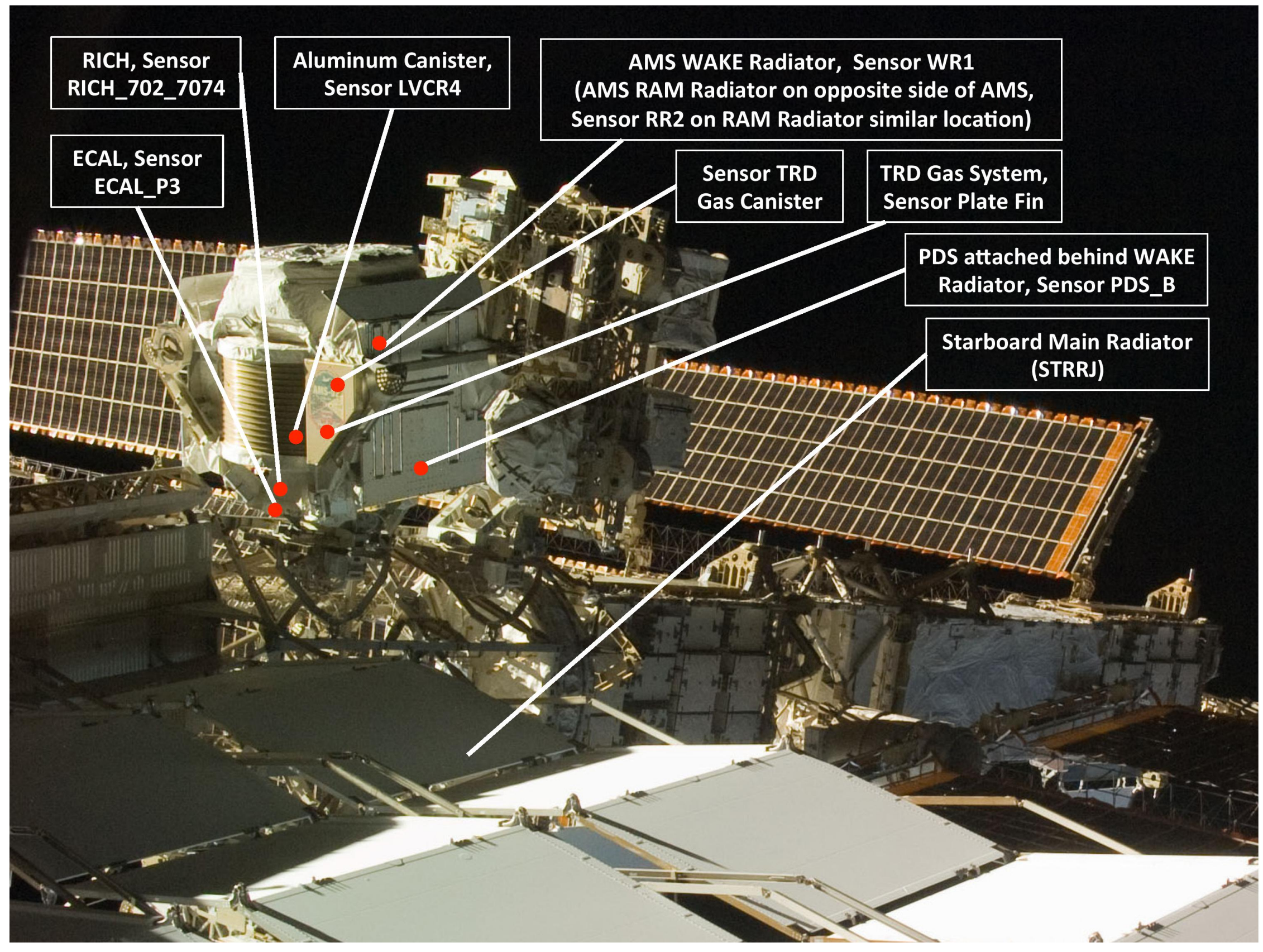

Figure 6: On orbit photograph (credit NASA) showing locations of the ISS Starboard Main Radiator and AMS temperature sensors. 


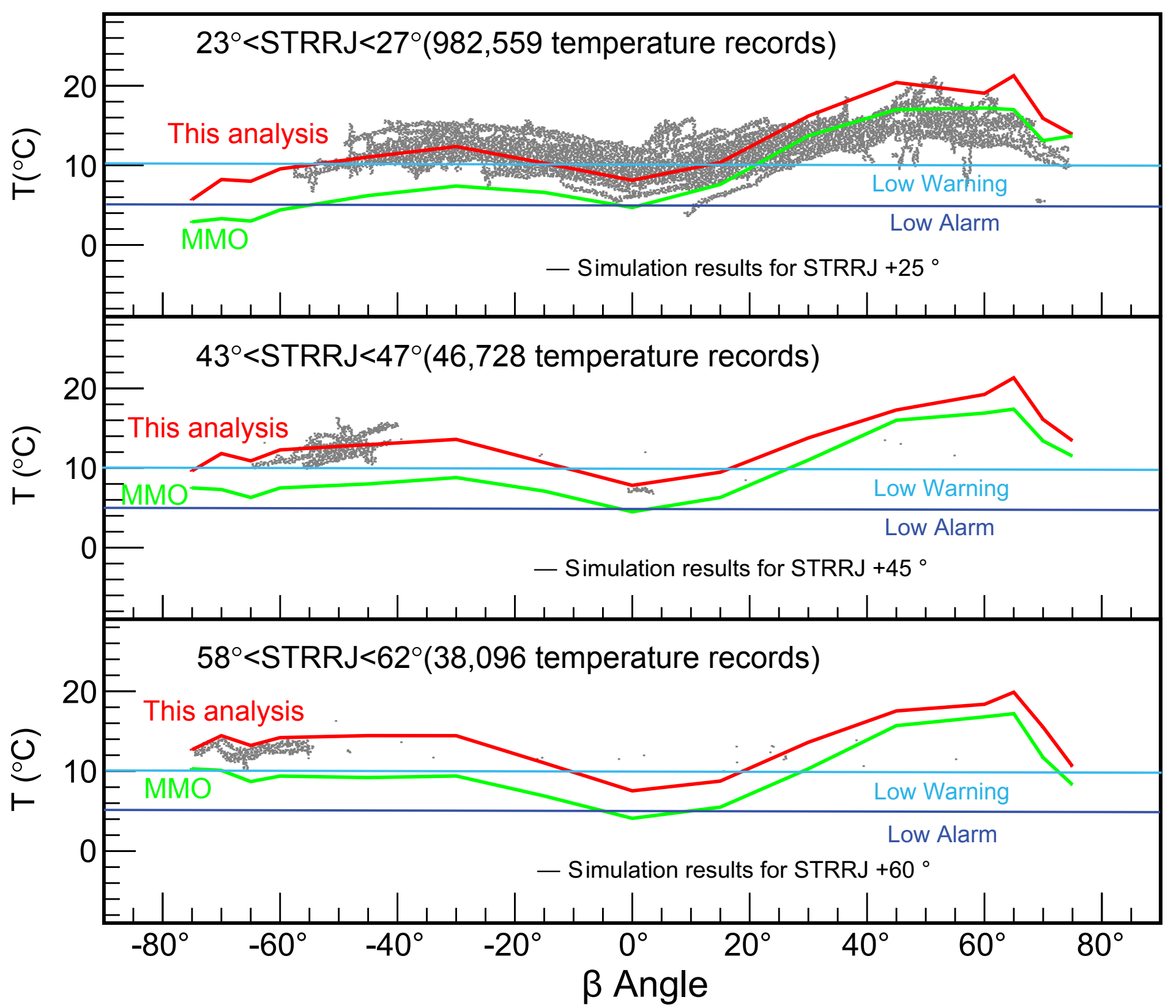

Figure 7: TRD Gas Canister sensor's temperature flight data records (grey dots) from 19 May 2011 to 24 Dec. 2013 compared with simulation results from this analysis (red curves) and from the NASA MMO analysis (green curves) for three different positions of the ISS Starboard Main Radiator (STRRJ). 


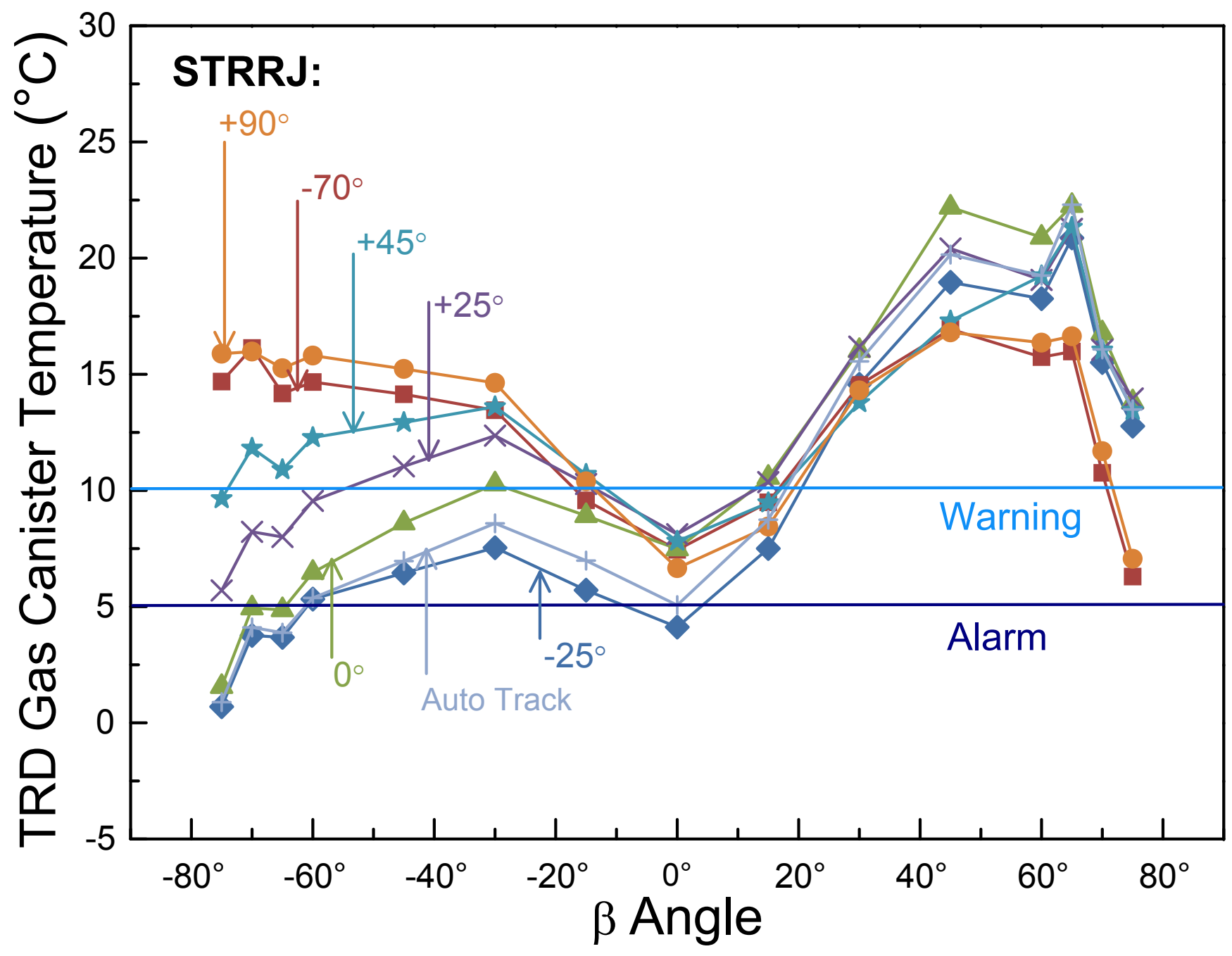

Figure 8: Simulation results of the TRD Gas Canister temperature variation with $\beta$ Angle for different STRRJ positions (low warning limits: $+10{ }^{\circ} \mathrm{C}$ and low alarm limits: $+5{ }^{\circ} \mathrm{C}$ ).

TRD Gas Canister simulation temperature results with different $\beta$ Angle are shown as:

$\square$ for STRRJ $-70^{\circ}, \diamond$ for STRRJ $-25^{\circ}, \Delta$ for STRRJ $0^{\circ}, X$ for STRRJ $+25^{\circ}, \star$ for STRRJ $+45^{\circ}$,

for STRRJ $+90^{\circ},+$ for STRRJ Auto Track. Colored lines connect the results for each STRRJ position to guide the eye. 


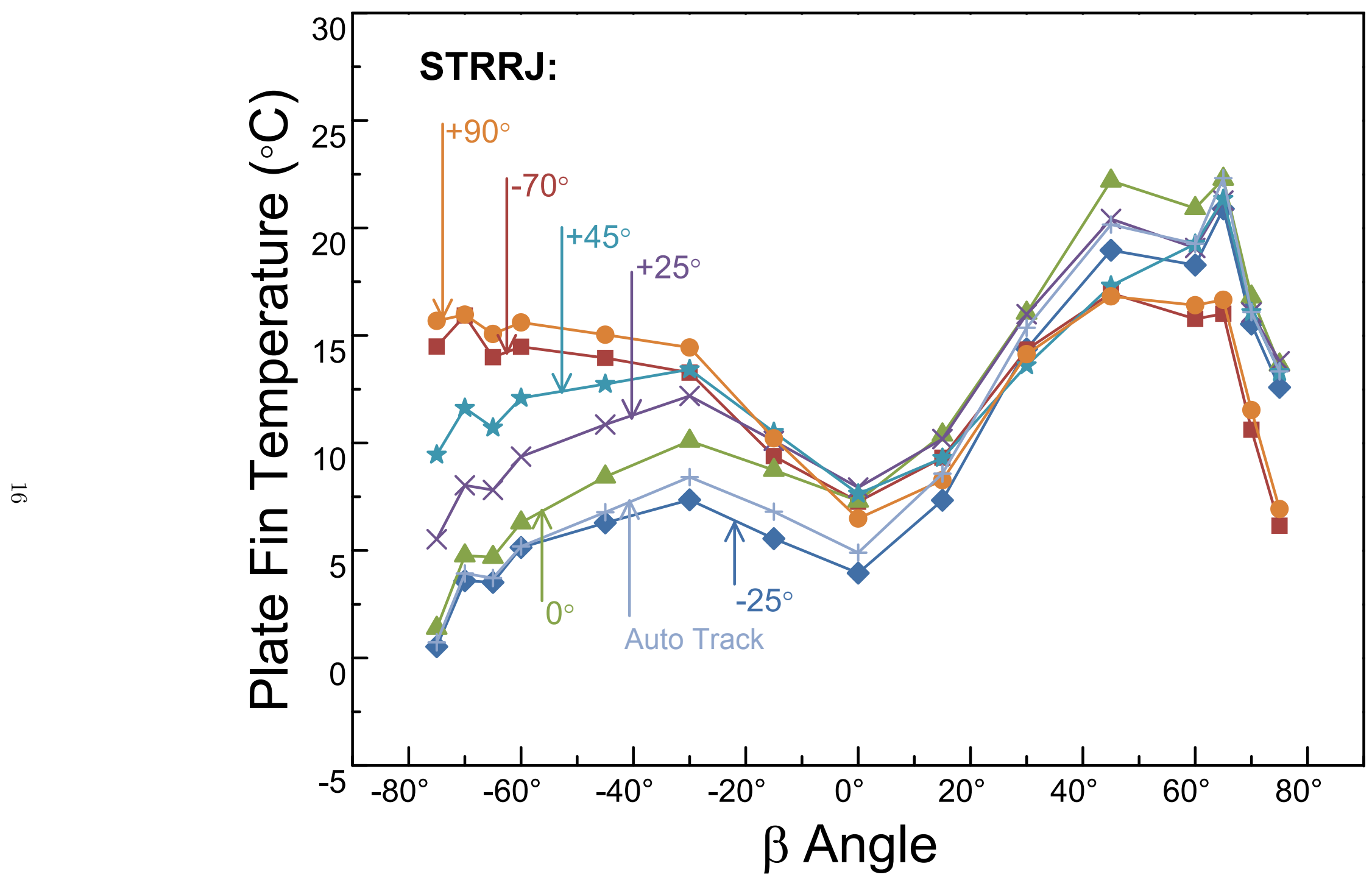

Figure 9: Simulation results of the Plate Fin temperature variation with $\beta$ Angle for different STRRJ positions (warning limits: low -15 ${ }^{\circ} \mathrm{C}$ and high $+60{ }^{\circ} \mathrm{C}$ ). The convention for symbols and lines is the same as in Fig. 8 . 


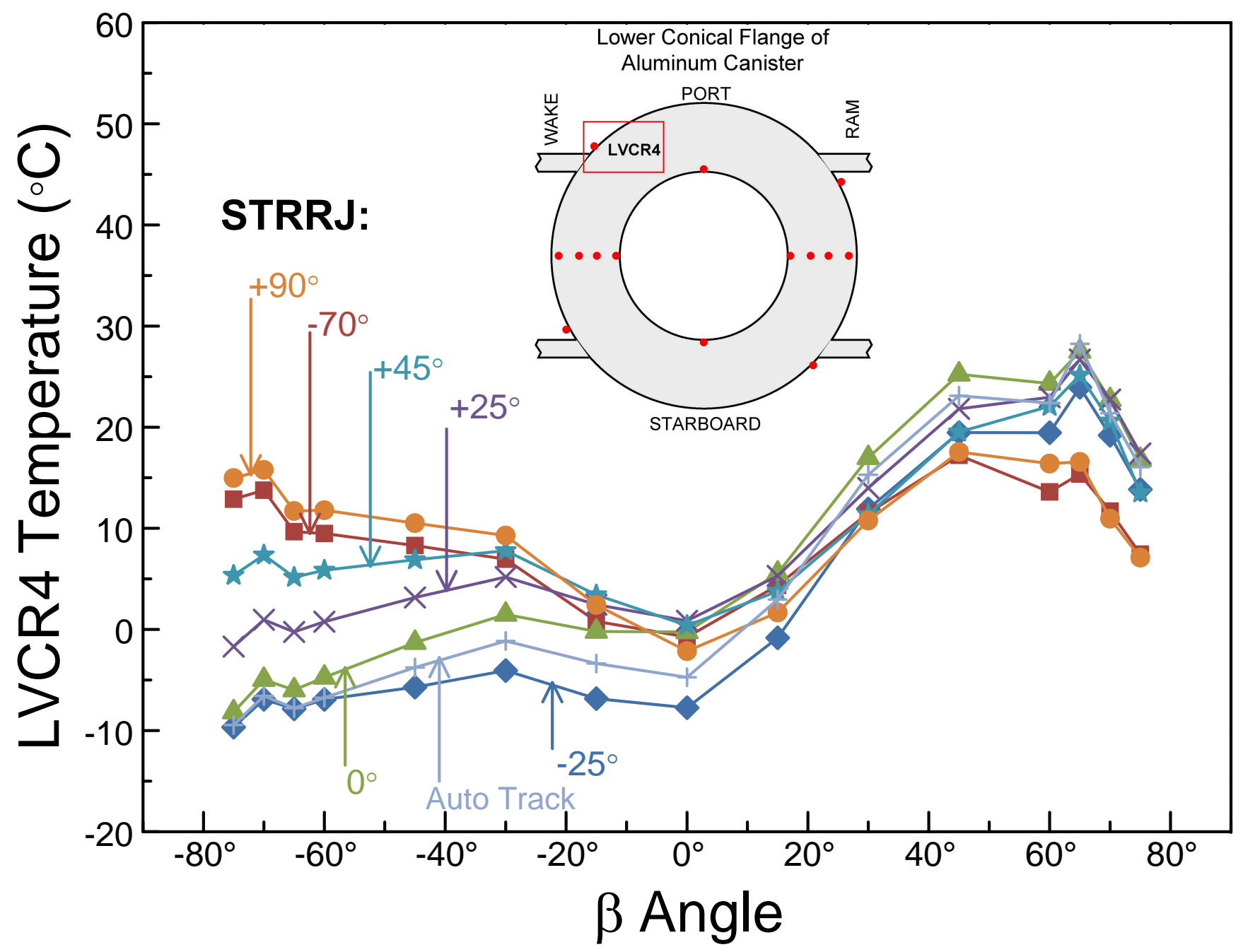

Figure 10: Simulation results of the LVCR4 (in red rectangle) temperature variation with $\beta$ Angle for different STRRJ positions (warning limits: low $-15^{\circ} \mathrm{C}$ and high $+45^{\circ} \mathrm{C}$ ). The top center insert figure shows Aluminum Canister temperature sensors' locations as red dots (top view). The convention for symbols and lines is the same as in Fig. 8. 


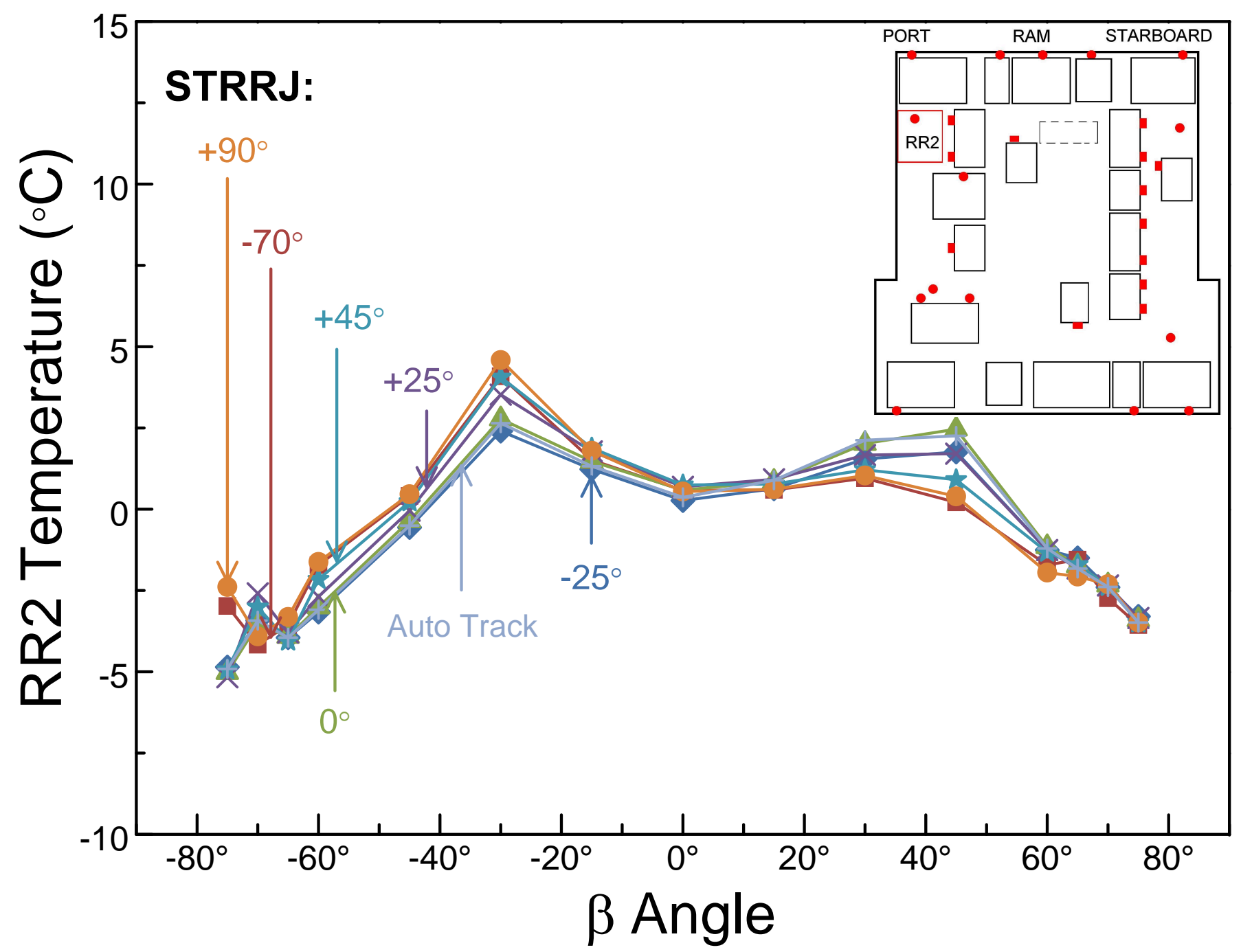

Figure 11: Simulation results of the RR2 temperature variation with $\beta$ Angle for different STRRJ positions (warning limits: low $-15^{\circ} \mathrm{C}$ and high $+45^{\circ} \mathrm{C}$ ). The top right insert figure shows RAM Radiator temperature sensor locations as red dots, rectangles with solid lines are electronic boxes with the RR2 marked with a red rectangle, and the dashed rectangle is a hole in the RAM Radiator. The convention for symbols and lines is the same as in Fig. 8. 


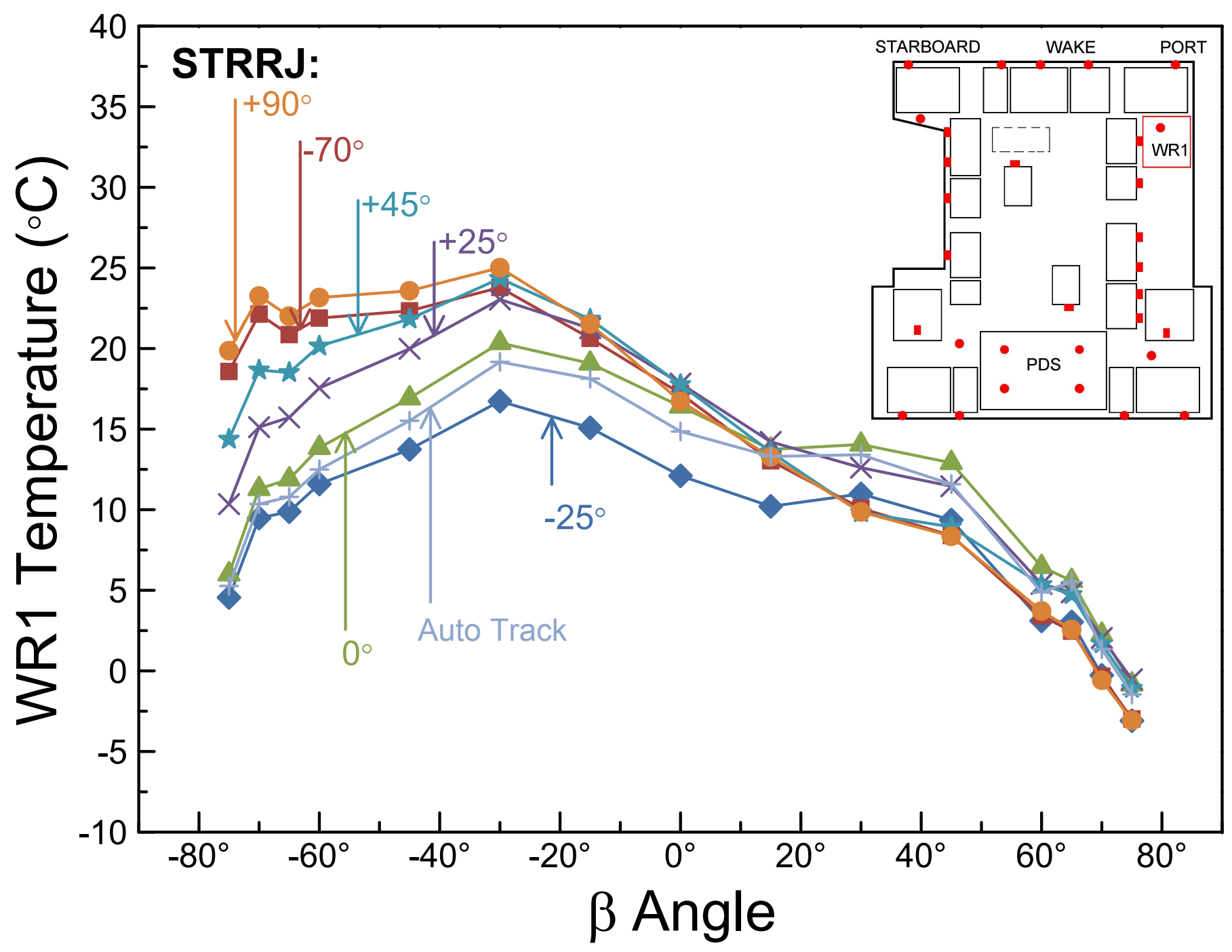

Figure 12: Simulation results of the WR1 temperature variation with $\beta$ Angle for different STRRJ positions (warning limits: low -15 ${ }^{\circ} \mathrm{C}$ and high $+45^{\circ} \mathrm{C}$ ). The top right insert figure shows WAKE Radiator temperature sensor locations as red dots, rectangles with solid lines are electronic boxes with the WR1 rectangle in red, and the dashed rectangle is a hole in the WAKE Radiator. The convention for symbols and lines is the same as in Fig. 8. 


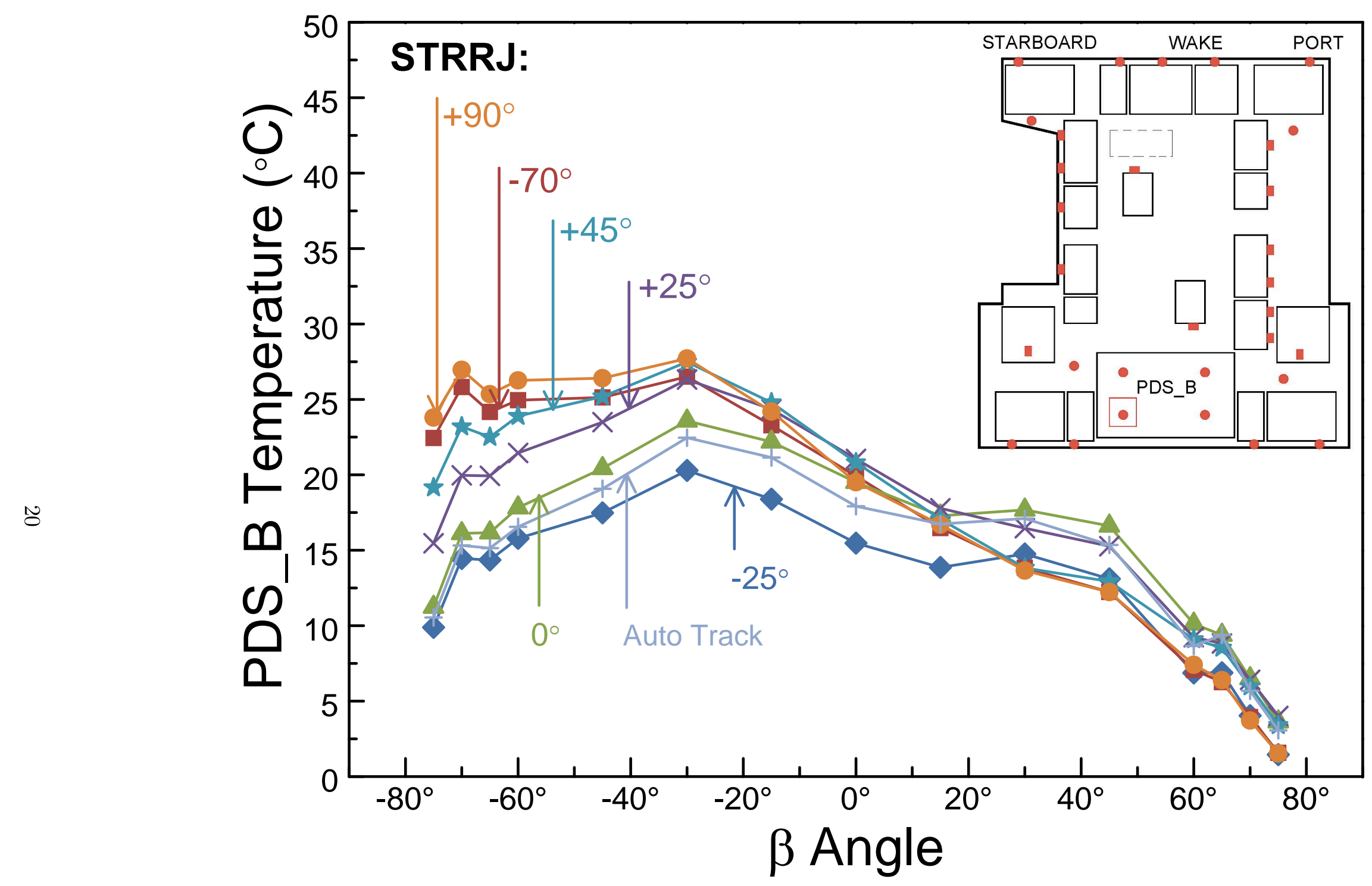

Figure 13: Simulation results of the PDS_B temperature variation with $\beta$ Angle for different STRRJ positions (warning limits: low -20 ${ }^{\circ} \mathrm{C}$ and high $+43{ }^{\circ} \mathrm{C}$ ). The top right insert figure shows the location of the PDS on the inside of the WAKE Radiator with PDS_B marked with a red rectangle. The convention for symbols and lines is the same as in Fig. 8. 


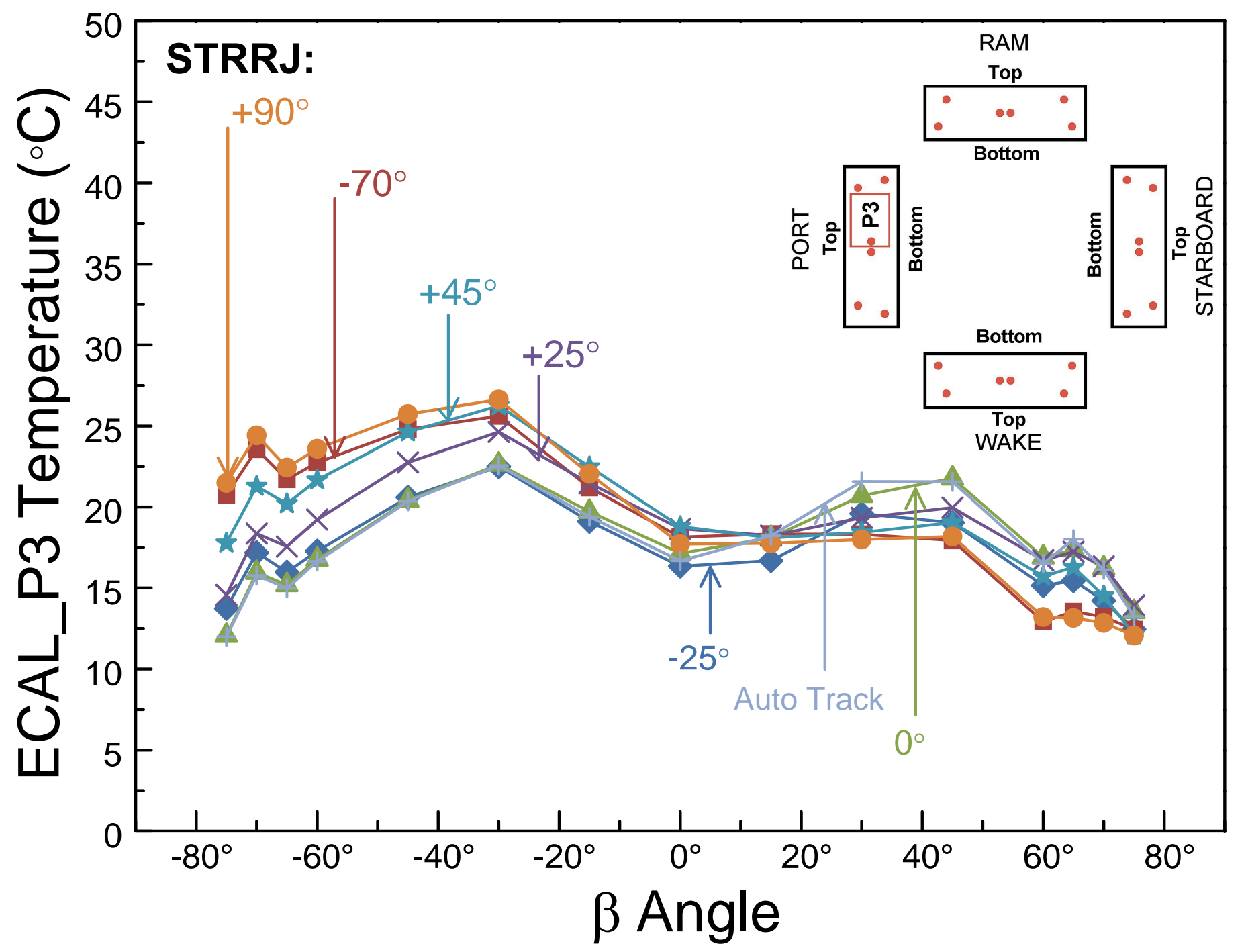

Figure 14: Simulation results of the ECAL_P3 (in red rectangle) temperature variation with $\beta$ Angle for different STRRJ positions (warning limits: low $-15{ }^{\circ} \mathrm{C}$ and high $+35{ }^{\circ} \mathrm{C}$ ). The top right insert figure shows an unfolded view of the ECAL temperature sensor locations as red dots. These sensors are located on radiator plates (black rectangles) outside the ECAL photo-tubes. The convention for symbols and lines is the same as in Fig. 8 . 


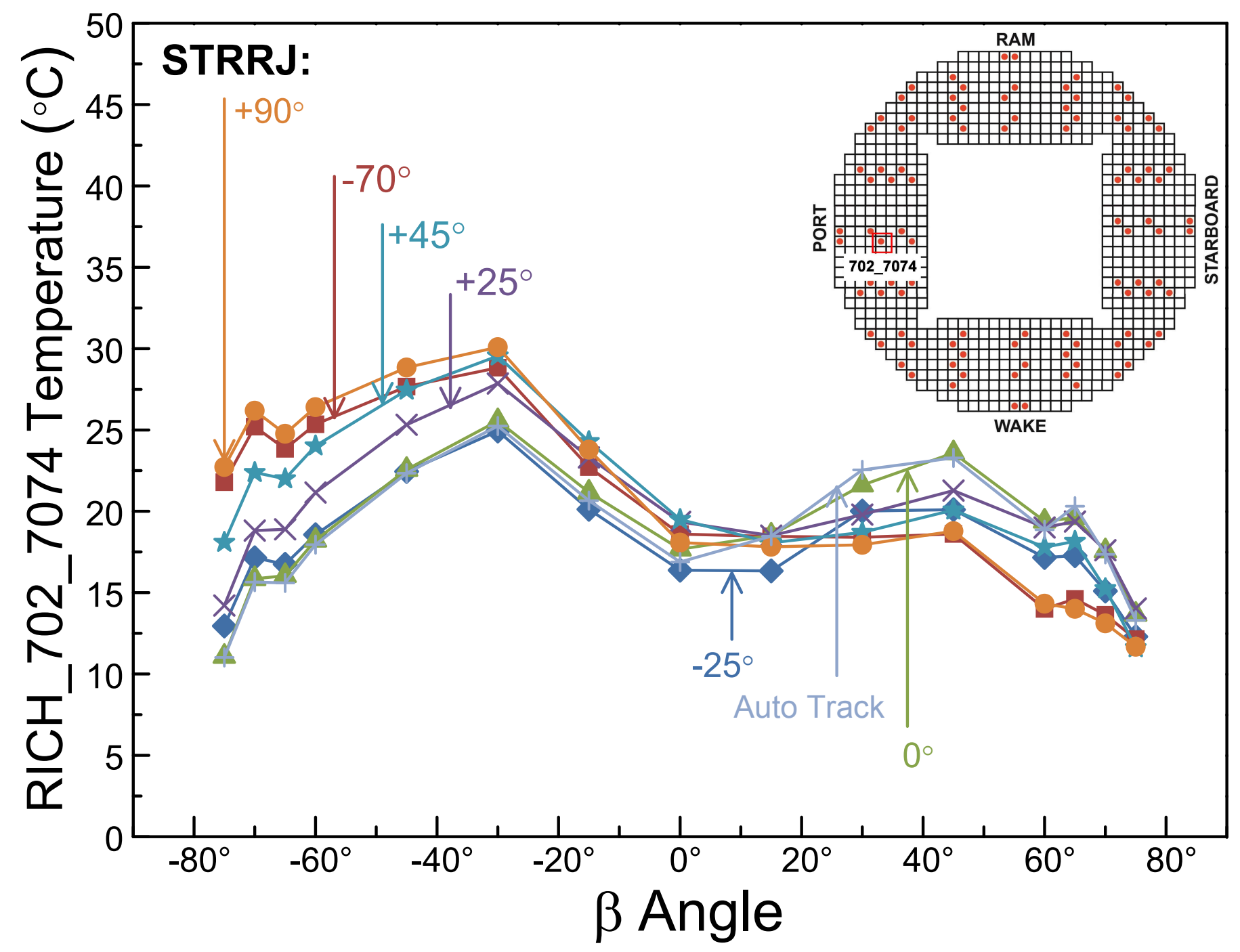

Figure 15: Simulation results of the RICH_702_7074 (in red rectangle) temperature variation with $\beta$ Angle for different STRRJ positions (warning limits: low $-25^{\circ} \mathrm{C}$ and high $+45^{\circ} \mathrm{C}$ ). The top right insert figure shows a view of the RICH temperature sensors' locations as red dots and PMT positions as black squares. The convention for symbols and lines is the same as in Fig. 8. 